\title{
Um breve panorama acerca da terminologia utilizada no âmbito do desenvolvimento de identidade visuais
}

\section{A brief overview of the terminology used in the development of visual identities}

\author{
André Antônio de Souza, Madalena Ribeiro Grimaldi
}

design gráfico, marcas, identidade visual, terminologia

\begin{abstract}
Este artigo apresenta uma discussão, no campo do design, acerca dos principais termos empregados no desenvolvimento de identidades visuais. Em sua execução, adotou-se o seguinte procedimento metodológico: a partir de uma abordagem do conceito de terminologia, no que tange ao seu objeto de estudo e propósito maior, procurou-se determinar o sentido destas expressões de acordo com obras de referência e autores consagrados da área. Tais informações, que proporcionaram um breve panorama sobre a questão, foram então submetidas a uma análise. Concluiu-se que a legitimidade dos diferentes significados conferidos aos vocábulos, indicada pela sua inclusão nos dicionários, aponta possivelmente que os embates entre os defensores destas compreensões díspares são impertinentes. Salienta-se, desta forma, que cada profissional pode assim fazer uso dos termos com a acepção de sua preferência, sem considerar inadequada uma opinião diferente, na medida em que a terminologia, enquanto disciplina, leva em conta esta diversidade intrínseca ao desenvolvimento natural da língua.
\end{abstract}

graphic design, brands, visual identity, terminology

This article presents a discussion, in the field of design knowledge, about the main terms used in the development of visual identities. In its execution, the following methodological procedure was adopted: from an approach to the concept of terminology, with regard to its object of study and greater purpose, we sought to determine the meaning of these expressions according to reference works and renowned authors in the area of graphic design. This information, which provided a brief overview of the issue, was then submitted to an analysis. It was concluded that the legitimacy of the different meanings given to the words, indicated by their inclusion in dictionaries, possibly denotes that the clashes between the defenders of these disparate understandings are impertinent. It should be noted, therefore, that each professional can use the terms with the meaning of their preference, without considering a different opinion inappropriate, as terminology, as a discipline, takes into account this diversity, intrinsic to the natural development of the language.

\section{Introdução}

Explicar o que é design tem constituído, ao longo do tempo, uma tarefa difícil, de tal forma que "não faltam no meio profissional definições" suscitando "debates infindáveis" (Cardoso, 2004, p. 14). Isto talvez se deva à sua condição interdisciplinar, na medida em que "tende ao infinito" ao "dialogar em algum nível com quase todos os outros campos de conhecimento [...] como um campo ampliado que se abre para diversas outras áreas" (Cardoso, 2016, p. 234).

Anais do $10^{\circ} \mathrm{CIDI}$ e $10^{\circ} \mathrm{CONGIC}$

Kelli C.A.S. Smythe, Rafael de Castro Andrade (orgs.)

Sociedade Brasileira de Design da Informação - SBDI

Curitiba | Brasil | 2021
Proceedings of the $10^{\text {th }} \mathrm{CIDI}$ and $10^{\text {th }}$ CONGIC

Kelli C.A.S. Smythe, Rafael de Castro Andrade (orgs.)

Sociedade Brasileira de Design da Informação - SBDI Curitiba | Brazil | 2021 
Algo similar ocorre no âmbito de sua terminologia, notadamente a que concerne ao desenvolvimento de identidades visuais, pois existem divergências quanto ao significado de alguns termos empregados como demonstram as eternas disputas em torno da propriedade ou impropriedade de expressões como "logotipo" e "logomarca".

Este artigo destaca o ponto de vista de obras de referência e de autores selecionados acerca de algumas destas expressões, e uma análise deste conjunto de definições que proporciona um breve panorama acerca do tema. Não se pretende, contudo, acirrar os referidos embates, encerrar a questão, ou mesmo empreender um estudo detalhado que compete ao domínio da linguística, mas fornecer uma compreensão atualizada desta visão, que concilia a importância dos estudos terminológicos com a natureza dinâmica dos idiomas.

\section{O conceito de terminologia e sua importância}

De acordo com Barbosa (1991), "qualquer ciência tem necessidade de um conjunto de termos rigorosamente definidos, pelos quais designa as noções que Ihe são úteis". Esta coletânea de palavras "constitui [...] a sua terminologia" (1991, p. 185-186).

Pontes (1997) explica, que apenas no século XX ela adquiriu status de disciplina independente, e hoje (embora nem todos a considerem assim), é reconhecida cada vez mais como um tópico importante para o currículo do ensino contemporâneo, uma vez que o emprego de termos técnicos estabelecidos de modo incorreto, ou o seu uso inconsistente, pode originar problemas didáticos a docentes e discentes.

Ademais, sem a univocidade que the caracteriza, "especialistas não conseguiriam se comunicar, repassar seus conhecimentos, nem tampouco representar" estas informações "de forma organizada" (Dias, 2000, p. 91), especialmente quando advindos de áreas díspares. Fica evidente assim a dimensão da sua importância.

É preciso ter-se em mente, entretanto, que o "termo", seu objeto de estudo, "é essencialmente um signo linguístico", composto "de uma denominação (significante) e um conceito (significado)", e que a questão mais importante da área não é saber o que ele significa, mas determinar "qual é a forma linguística que representa uma dada noção". Constitui assim "um símbolo convencional veiculador de uma noção definida num certo domínio do saber" (Pontes, 1997, p. 47).

Apoiado nos autores supracitados, compreendemos que os dicionários, ao atestarem a existência dos vocábulos, levam em conta o seu étimo, mas consideram acima de tudo a forma como são entendidos e aceitos por uma parcela significativa da população. Refletem, portanto, o emprego que as pessoas fazem destes termos. Desta forma, certas expressões, ao se tornarem de uso comum, passam a figurar nos léxicos, ainda que seu significado não possa ser compreendido plenamente a partir de seu sentido etimológico. 


\section{A terminologia utilizada no desenvolvimento de identidades visuais e seus possíveis sentidos}

Segue-se uma amostra de determinadas expressões empregadas no âmbito do desenvolvimento de identidades visuais e seu significado na visão de autores e de publicações de referência selecionados, junto com considerações acerca de suas opiniões.

Identidade visual. O dicionário on-line Michaelis define identidade como uma "série de características próprias de uma pessoa ou coisa por meio das quais podemos distingui-las" (IDENTIDADE, 2019), tal como os itens que permitem o reconhecimento de uma entidade ou instituição. Como a identificação se dá em função do nível em que estas informações ficam sedimentadas na lembrança, constituem fatores importantes do processo: a memória, na ótica de Cardoso (2016), o mecanismo primordial de sua construção, e o princípio da repetição, na medida em que estes dados são memorizados ao serem sucessivamente assimilados. Um fator adicional será considerado adiante.

Conforme Peón (2003), integram os aspectos distintivos de uma organização, tudo aquilo que "voluntariamente ou não" participa na formação da sua imagem na mente do público, "desde a forma como seus funcionários lidam e se apresentam para os clientes até as estratégias de marketing assumidas, as campanhas publicitárias, a arquitetura, a decoração, [...] a localização de seus pontos de venda ou de serviço" e "a embalagem de seus produtos" (2003, p. 13-14). Esta imagem pode vir a ser positiva ou mesmo negativa. A identidade, portanto, pode ser construída para transmitir valores e qualidades, assim como uma pessoa que se veste de determinado modo para expressar a sua personalidade ou a função que exerce.

Identidade visual é aquela estabelecida por itens visuais, sobretudo os de natureza gráfica, tal como exposto por Strunck (2003), que a entende como o "conjunto de elementos gráficos que irão formalizar a personalidade visual de um nome, ideia, produto ou serviço" (2003, p. 57), cuja contribuição na formação identitária se dá, conforme Consolo (2015), pelo seu "uso sistêmico e, principalmente" pela "sua constância formal" (2015, p. 21).

Logo, é composta por unidades consistentemente concebidas, normatizadas e organizadas, como padrões cromáticos, marcas, símbolos, logotipos, grafismos, imagens, fontes tipográficas e composições específicas, formando um sistema coeso para promover a identificação notória e positiva de uma organização. Alexandre Wollner (2003), compreende a expressão de modo semelhante, quando expõe que a "identidade visual" do tipo corporativo, constitui um processo "de programação sistêmica que envolve signos e suas aplicações através de modulação e relações proporcionais entre diferentes meios e suportes de comunicação na busca de uma linguagem coesa e unificada, representativa de instituições, empresas ou corporações" (2003, p. 315).

Assim, um terceiro princípio importante no seu desenvolvimento é, por conseguinte, o contraste, na medida em que se almeja que estas identidades se destaquem de suas concorrentes no cenário gráfico (Figura 1). 
Figura 1: Elementos de identidade visual do Bob's: marca, embalagens e fachada de loja. Fonte: Marca: httb:mundodasmarcas.bloaspot.com/2008/05/bobs-fast-food-made-in-brazil.html, Embalagens e fachada:
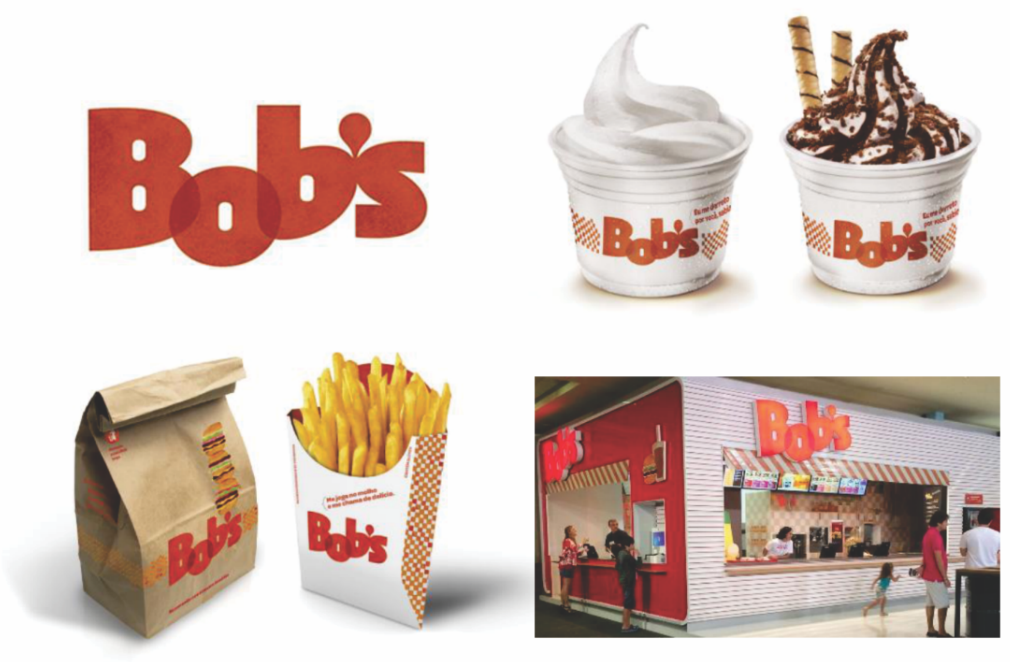

Logotipo. O dicionário Aurélio (Ferreira, 1993) descreve logotipo como um "símbolo formado por palavra ou letra com desenho característico para representar visualmente uma empresa, um produto, etc" (Ferreira, 1993, p. 199). Vários autores concordam com esta explicação. Chaves (1999), por exemplo, o define como "a versão gráfica [...] do nome da marca" (1999, p. 199). Para Strunck (2003) o termo se refere à "particularização da escrita de um nome" (2003, p. 70). Peón (2003) o descreve como a "forma particular e diferenciada com a qual o nome" de uma "instituição é registrado nas aplicações" (2012, p. 28), e Wheeler (2012), como uma representação de caráter tipográfico, composta por uma ou várias palavras, compondo uma estrutura que eventualmente pode "integrar elementos abstratos ou pictóricos" (2012, p. 64) (Figura 2).

Figura 2: Logotipos. Fonte: Oslo: https://www.brandsoftheworld.com/logo/oslo, Eternit: https://www.brandsoftheworld.com/logo/eternit, Bob's: https://www.brandsoftheworld.com/logo/bobs-0.

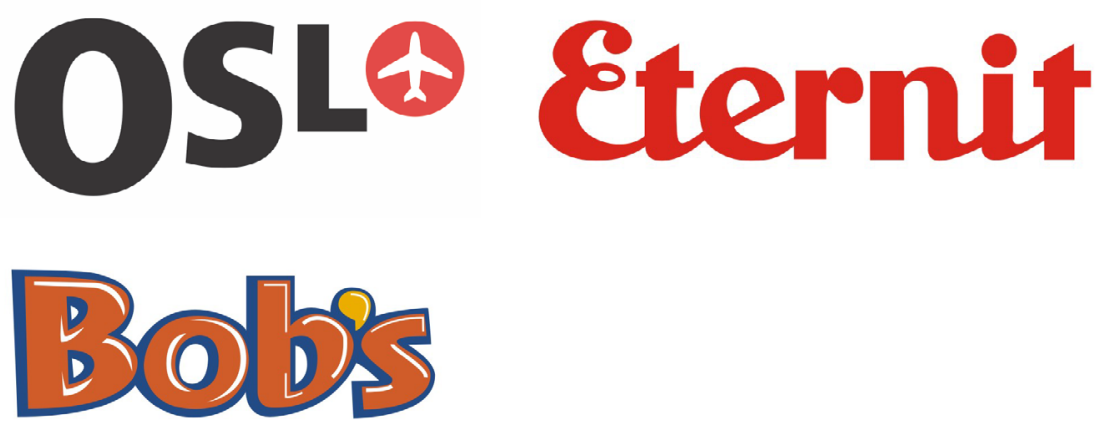

\footnotetext{
1“la versión grafica [...] del nombre de marca”.
} 
Apesar desta acepção da palavra como um elemento de caráter tipográfico, inúmeras pessoas a empregam com um sentido expandido, como uma representação que pode incluir outras formas gráficas. Confirmando este entendimento, o dicionário Cegalla (2008) o descreve como sinônimo de logomarca, expressão que também possui esta denotação e que será examinada à frente. Na linguagem coloquial muitos se referem ao termo simplesmente como o "logo", uma forma reduzida.

Símbolo. Strunck (2003) define símbolo como "sinal gráfico, que com o uso, passa a identificar um nome, ideia, produto ou serviço" (2003, p. 71). Peón (2003) explica que a condição para que um elemento atue como um símbolo, é que ele possa ser aplicado isoladamente de um logotipo, (em sua acepção enquanto manifestação tipográfica), senão constitui-se em simples grafismo. Algumas instituições, conforme pontua Wheeler (2012), apresentam apenas símbolos em suas assinaturas corporativas, dispensando o logotipo, como a Target, a Apple e a Nike (Figura 3).

Figura 3: Símbolos. Fonte: Kibon: https://www.brandsoftheworld.com/logo/kibon-1, Nestlé: https://www.brandsoftheworld.com/logo/nestle-0, Supervia: Imagem digitalizada pelo autor.
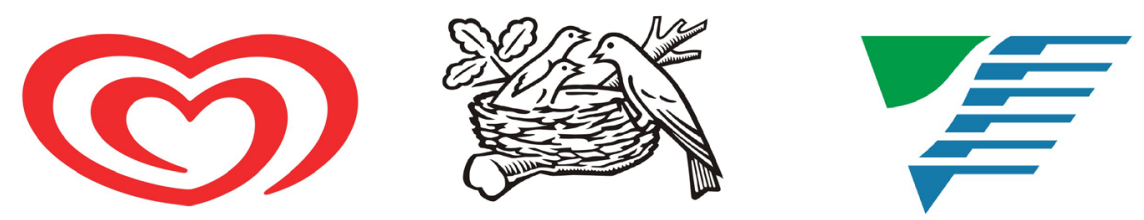

Também para este termo existe uma segunda acepção ampliada, pois o dicionário Aurélio (Ferreira, 1993) define a palavra como "o que representa ou substitui outra coisa; o que evoca, representa ou substitui algo abstrato ou ausente" (1993, p. 291). Este entendimento da expressão parece ter origem na semiótica, onde, de acordo com Santaella (1995 e 2012), o signo é também assim compreendido, ou seja, como "algo [...] determinado por alguma outra coisa que ele representa" (1995, p. 81), ao passo que o símbolo constitui um tipo específico de signo, no qual a relação "com o objeto que [...] representa depende de um caráter imputado, arbitrário", dado que se baseia numa "convenção de que ele será" entendido "como representando seu objeto" (2012, p. 133).

Qualquer item, portanto, pode atuar como símbolo, na medida em que é usado como representação de outra ocorrência. Muitos o empregam com este sentido, inclusive como sinônimo de logomarca, para referir-se à representação visual de uma entidade, independente de seus elementos constituintes. 
Marca. Para Consolo (2015) o termo abrange o conjunto de elementos visuais e verbais que compõem a identidade máster de uma organização e pode ser constituído por um símbolo, um logotipo ou pela soma de ambos. Esta expressão visual é passível de registro junto ao Instituto Nacional da Propriedade Industrial - INPI ${ }^{2}$. A autora ainda ressalta que a palavra procede do étimo "marka", germânico, e significa "sinal", designando um "sinal distintivo cujas funções principais são identificar a origem e distinguir produtos ou serviços de outros idênticos, semelhantes ou afins de origem diversa" (MANUAL, 2017).

Cabe destacar, além disso, que quando esta representação é formada por um logotipo e um símbolo, acompanhados ou não por grafismos, e as vezes por uma frase curta conhecida como tagline, alguns autores a denominam como assinatura visual (Figura 4).

Figura 4: Elementos da marca Marisa, símbolo, tagline e logotipo. Fonte: https://www.brandsoftheworld.com/logo/marisa-0.

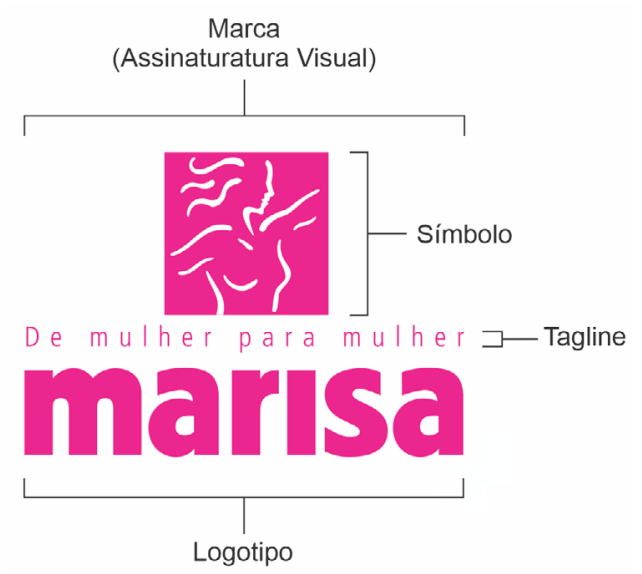

Algumas marcas apresentam uma conformação "intrinsecamente ligada ao nome da organização", com elementos que nunca aparecem isolados (Wheeler, 2012, p. 72). Este modelo de representação, com símbolo e logotipo mutuamente dependentes, numa estrutura gráfica única, costuma ser designado emblema, e denota assim, um tipo específico de marca $^{3}$ (Figura 5).

\footnotetext{
${ }^{2}$ Este registro é regido no Brasil pela Lei 9.279 de 1996 (Lei de Propriedade Industrial) que estabelece em seu Art. $122^{\circ}$ que "são suscetíveis de registro como marca os sinais distintivos visualmente perceptíveis" (BRASIL, 1996).

${ }^{3}$ Outro tipo é a chamada marca tridimensional, que envolve, conforme o INPI, "o sinal constituído pela forma plástica distintiva em si, capaz de individualizar os produtos e serviços a que se aplica" (MANUAL, 2017). Cabe ressaltar que sob o ponto de vista deste órgão, esta não consiste necessariamente numa versão tridimensional de uma representação bidimensional na acepção de Consolo (2015), e se refere à forma plástica de produtos ou mesmo embalagens, tal qual a famosa garrafa da Coca-Cola, um caso clássico.
} 
Figura 5: Emblemas. Fonte: Rotary: https://www.brandsoftheworld.com/logo/rotary-international-0, Cruzeiro: https://www.brandsoftheworld.com/logo/cruzeiro, UERJ:

http://www.intranet.dep.uerj.br/arqs/logos/UERJ_LOGO_COR.jpg.
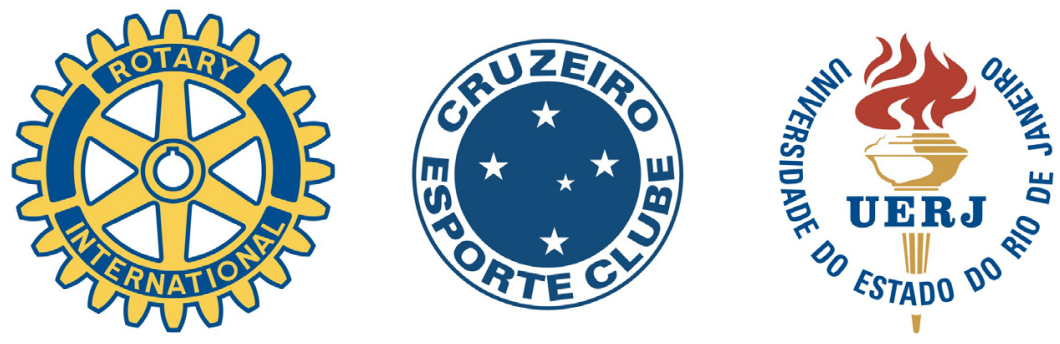

Ao passo que algumas entidades não possuem símbolo, apenas logotipo, outras, por vezes, o ostentam isoladamente, e há aquelas que aboliram o logotipo ficando apenas com o símbolo. Peón (2003) explica que não é incomum utilizar-se marca para referir-se a quaisquer destas ocorrências e não ao conjunto específico destas unidades, a exemplo de Wollner que a emprega com esta acepção no documentário "Alexandre Wollner e a Formação do Design Moderno no Brasil" (Alexandre..., 2005). Para a autora, o termo constitui assim, um elemento que sintetiza os demais e os suplanta, correspondendo ao sentido mais aberto de símbolo, já apresentado, e equivalente à logomarca.

Marca é talvez a expressão de significado mais amplo no âmbito da terminologia considerada neste trabalho, pois pode ser compreendida também enquanto manifestação intangível. Concordemente, Neumeier (2008) explica, que além da visão, ela "pode envolver outros sentidos, como o olfato, o tato, o paladar ou a audição" (2008, p. 88). Em vista disso, há que se considerar a existência de outras versões que podem atuar nos sentidos do olfato e da audição. Esta última é expressa, a título de exemplo, na "experiência de voar pela United Airlines [...] inextricavelmente ligada" à música "Rhapsody in Blue" de George Gershwin e na "marca auditiva" característica da Intel Inside ${ }^{4}$ (Neumeier, 2008, p. 88). Este entendimento do termo aplica-se também quando do seu emprego para fazer referência às entidades, produtos e serviços em si ${ }^{5}$ e não somente às suas representações visuais.

Em vista desta dimensão imaterial da palavra, Neumeier (2008) assevera que ela não é definida por corporações, mas por pessoas. Assim preconiza que "marca não é o que você diz que ela é", mas "o que OS OUTROS dizem que ela é" (2008, p. 3), na medida em que pode ser compreendida como uma "percepção íntima" ou "sentimento visceral de uma pessoa em relação a um produto, serviço ou empresa". De acordo com este pensamento, uma instituição só pode afirmar que possui uma marca, "quando um número suficiente de pessoas atinge o mesmo sentimento visceral" (2008, p.2) em relação à entidade.

\footnotetext{
${ }^{4}$ Intel Inside é um selo de qualidade criado na década de 1990 pela empresa para enfatizar que o computador utilizava o processador da marca e não o de seus concorrentes como a AMD. Seu último lançamento, em 2015, foi a sexta geração dos processadores Intel Core, o Skylake.

${ }^{5}$ Um exemplo é o emprego de marca para fazer referência aos nomes de entidades, produtos ou serviços.
} 
Logomarca. Esta é sem dúvida a palavra mais controversa na questão da nomenclatura, sendo frequentemente referida, na linguagem coloquial, como a "logo", uma forma reduzida da expressão. Dentre os que a rejeitam, alguns costumavam afirmar que ela não possui etimologia expressiva e que não é empregada em outros países, constituindo um neologismo brasileiro, ponto de vista que tem sido contestado.

Cristian (2017), por exemplo, pontua que os questionamentos quanto à sua etimologia não são válidos, uma vez que este campo do conhecimento estuda como as palavras surgiram e evoluíram, sem indicar de forma alguma, que cada qual tenha de derivar de outra com sentido completamente lógico, ou seja, a disciplina considera como as expressões aparecem, mas nunca ditam como devem surgir.

Quanto à ideia de que a palavra seria originária de um processo de neologismo, o autor ressalta que isso não representa nenhum demérito, já que este é um fenômeno normal, onde novas palavras são criadas e incorporadas ao vocabulário cotidiano sem maiores dificuldades. Em um sentido mais amplo, porém, o professor Cláudio Moreno, citado por Eichlig (Moreno apud Eichlig, 2018), preconiza que entre os estudiosos da linguística, tem sido muito comum a recusa do conceito de neologismo, pois ele parte da premissa absolutamente equivocada de que exista um ponto fixo no idioma, a partir do qual se possa dizer o que é novo.

Em relação ao uso no exterior, tanto Eichlig (2018), quanto Sebastiany (2009) atestam com exemplos, que a palavra é utilizada. Além disso, Sebastiany (2009) relata o emprego adicional de outras expressões ${ }^{6}$ vinculadas ao desenvolvimento de identidades visuais sem um sentido único, designando ora símbolo, ora logotipo e ora assinatura visual, evidenciando que a imprecisão da terminologia nesta área não é restrita ao Brasil.

Quanto ao sentido da palavra, Peón (2003) a entende como correspondente à marca na acepção de Consolo (2015), e Strunck (2003) como sinônimo de logotipo, no seu entendimento enquanto elemento tipográfico. O vocábulo, entretanto, é utilizado de forma mais abrangente, tal qual expresso no dicionário Cegalla (2008): "símbolo gráfico e visual padronizado que identifica uma empresa, uma marca ou uma linha de produtos; logotipo" (2008, p. 545). Note-se que esta obra de referência associa a palavra tanto ao símbolo como ao logotipo.

Uma definição semelhante para o termo é apresentada no Guia ADG Brasil de Prática Profissional do Designer Gráfico (2004) que o descreve como "identificação genérica [...] para sinais diversos de um programa de identidade visual como logotipo, símbolo e marca" (2004, p. 183). A expressão designa assim qualquer elemento visual, empregado isoladamente ou como parte de um conjunto e que tenha a função de representar graficamente uma entidade, produto ou serviço.

\footnotetext{
${ }^{6}$ Algumas destas expressões são brand, brandmark e trademark, dentre outras, que não serão consideradas neste trabalho devido ao seu enfoque nos termos em português mais utilizados no Brasil.
} 


\section{Análise do panorama}

O breve panorama apresentado acima, relativo à acepção das palavras mais utilizadas no campo da criação de identidades visuais, mostrou que só há algum consenso quanto ao significado da expressão identidade visual. Para as demais, logotipo, símbolo e marca, existem duas possibilidades de entendimento, uma delas, estabelecida via origem etimológica e aceitação no domínio especializado do seu campo de conhecimento, que considera que cada qual possui peculiaridades específicas, e outro mais aberto e informal, consagrado via aceitação e uso popular, que as considera sinônimos de logomarca.

A inclusão destas duas possibilidades nos dicionários, indica que as disputas em torno da propriedade ou impropriedade destas manifestações, possam não fazer sentido, já que o seu emprego de modo coerente e dentro dos parâmetros descritos aqui são aceitáveis, levando-se em conta o desenvolvimento natural do idioma. A "variação é inerente à língua e reflete variações sociais", dado que o "signo é, por natureza, vivo e móvel, plurivalente" (Bakthin, 2006, p. 16).

Assim, no âmbito do desenvolvimento de identidades visuais, cada profissional pode fazer uso da terminologia da área segundo suas preferências pessoais, sem a necessidade de considerar inadequada uma opinião diferente. O fundamental, em qualquer texto acadêmico ou profissional, é que o autor conceitue qual nomenclatura está adotando e o sentido em que será empregada.

\section{Considerações finais}

Centrado no ponto de vista de determinados autores e obras de referência, que discutem sobre o significado de algumas das expressões mais utilizadas no âmbito do desenvolvimento de identidades visuais, foi possível relatar uma breve visão acerca do assunto.

Desta forma, verificou-se que o significado destas palavras foi estabelecido a partir de dois posicionamentos diferentes, e sua inclusão nos léxicos vêm indicando que ambas as formas de entendimento são aceitáveis, invalidando as eternas disputas acerca da propriedade ou impropriedade de alguns destes termos. Mais importante do que disputar a favor ou contra determinadas expressões é fazer-se compreender, utilizando-se para isso dos recursos que o idioma oferece.

Embora divergências terminológicas estejam presentes também em outros campos do saber, caber perguntar por que não foi estabelecida, neste caso, uma terminologia única, em vista da sua importância e das vantagens que representa, conforme salientado no início deste artigo, sobretudo para a atividade de ensino e pesquisa na área.

Não é fácil obter uma resposta para esta indagação, que parece revelar uma "contradição [...] entre a unicidade e a pluralidade da significação" (Bakthin, 2006, p. 16). Decerto a adoção de um ponto de vista singular poderia representar um reducionismo na riqueza das expressões. Outrossim, no âmbito das discussões sobre a regulamentação do design no Brasil, é possível que a ideia discutível de que a sua prática não implica riscos para a sociedade, e a subsequente dispensa de maiores preocupações com o seu exercício, possa estar contribuído para este panorama. 


\section{Referências}

Cardoso, R. (2004). Uma introdução à história do design. São Paulo: Edgard Blücher.

Cardoso, R. (2016). Design para um mundo complexo. São Paulo: Ubu Editora.

Barbosa, M.A. (1991). Lexicologia, lexicografia, terminologia: objeto, métodos, campo de atuação e de cooperação. Anais dos Seminários do GEL. Estudos Linguísticos XX. Disponível em <http://www.gel.hospedagemdesites.ws/arquivo/anais/1306849376_29.barbosa_maria.pdf>. Acesso em 12 Out. 2020.

Pontes, A. L. (1997). Terminologia Científica: O que é e como se faz. Revista de Letras da Universidade Federal do Ceará. v. 19, n. 1/2, 44-51.

Dias, C.A. (2000). Terminologia: conceitos e aplicações. Revista Ciência da Informação, v. 29, n.1, 90-92. Disponível em <http://revista.ibict.br/ciinf/issue/view/71>. Acesso em 12 Out. 2020.

IDENTIDADE. (2019). Michaelis Dicionário Brasileiro da Língua Portuguesa (on-line). Melhoramentos. Disponível em <https://michaelis.uol.com.br>. Acesso em 23 Ago. 2019.

Peón, M. L. (2003). Sistemas de Identidade Visual. Rio de Janeiro: 2AB.

Strunck, G. (2003). Como criar identidades visuais para marcas de sucesso: um guia sobre o marketing das marcas e como representar graficamente seus valores. Rio de Janeiro: Rio Books.

Consolo, C. (2015). Marcas: design estratégico. Do símbolo à gestão das identidades corporativas. São Paulo: Blücher.

Wollner, A. (2003). Alexandre Wollner: Design visual 50 anos. São Paulo: Cosac \& Naify.

Ferreira, A. B. H. (1993). Minidicionário da Língua Portuguesa. Rio de Janeiro: Nova Fronteira.

Chaves, N. (1999). La imagem corporativa: teoria y metodologia de la identificación institucional. Barcelona: Editorial Gustavo Gili.

Wheeler, A. (2012). Design de identidade da marca: guia essencial para toda a equipe de gestão de marcas. Porto Alegre: Bookman.

Cegalla, D. P. (2008). Dicionário Escolar da Língua Portuguesa. São Paulo: Companhia Editora Nacional.

Santaella, L. (1995). A Teoria Geral dos Signos. São Paulo: Editora Ática.

Santaella, L. (2012). Percepção: fenomenologia, ecologia, semiótica. São Paulo: Cengage Learning.

MANUAL de Marcas. (2017). Instituto Nacional da Propriedade Industrial. Disponível em <http://manualdemarcas.inpi.gov.br/>. Acesso em 31 Out. 2020.

ALEXANDRE Wollner e a Formação do Design Moderno no Brasil. (2005). Direção: Gustavo Moura. Produção: Alexandre Seara. Rio de Janeiro: Tecnopop.

Neumeier, M. (2008). The Brand Gap = O abismo da marca: como construir a ponte entre a estratégia e o design. Porto Alegre: Bookman. 
Cristian, L. (2017). Logomarca existe sim...só o seu orgulho não aceita. Disponível em $<$ https://clubedodesign.com/2017/logomarca-existe-sim-so-o-seu-orgulho-naoaceita/>.Acesso em 31 Out. 2020.

Eichlig, R. (2018). Por que é correto em N idiomas, menos em PT-BR? Disponível em $<$ https://temporalcerebral.com.br/logotipo-logomarca-existe-ou-nao/>. Acesso em 31 Out. 2020.

Sebastiany, G. (2009). Logomarca? Porque sim e porque não. Disponível em <https://webinsider.com.br/logomarca-porque-sim-e-porque-nao/>. Acesso em 31 Out. 2020.

ASSOCIAÇÃO DOS DESIGNERS GRÁFICOS DO BRASIL. (2004). O valor do design: guia ADG Brasil de prática profissional do designer gráfico. São Paulo: Editora Senac São Paulo.

Bakhtin, M. (2006). Marxismo e filosofia da linguagem. São Paulo: Hucitec.

\section{Sobre o(a/s) autor(a/es)}

André Antônio de Souza, Me., UERJ, Brasil <asouza@esdi.uerj.br>

Madalena Ribeiro Grimaldi, Dra., UFRJ, Brasil <mgrimaldi@eba.ufrj.br> 